\title{
Commentary: Malaria elimination in India and regional implications
}

\author{
Kwang Seung Park ${ }^{1}$, Sumera Kausar Malik ${ }^{1}$, Jung Hee Lee ${ }^{1}$, Asad Mustafa Karim ${ }^{1,2}$ and \\ Sang Hee Lee ${ }^{\text {** }}$ \\ ${ }^{1}$ National Leading Research Laboratory of Drug Resistance Proteomics, Department of Biological Sciences, Myongji \\ University, Yongin, South Korea, ${ }^{2}$ Department of Bioinformatics, Quaid-i-Azam University Islamabad, Islamabad, Pakistan
}

Keywords: malaria, prevalence, India, bordering countries, Plasmodium vivax, Plasmodium falciparum, drug resistance

\section{A commentary on}

\section{OPEN ACCESS}

Edited by:

Sunil Kumar Lal,

Monash University Malaysia, Malaysia

Reviewed by:

Paras Jain,

Albert Einstein College of Medicine,

United States

*Correspondence:

Sang Hee Lee

sangheelee@mju.ac.kr

Specialty section:

This article was submitted to

Infectious Diseases,

a section of the journal

Frontiers in Microbiology

Received: 02 August 2017

Accepted: 27 April 2018

Published: 15 May 2018

Citation:

Park KS, Malik SK, Lee JH, Karim AM and Lee SH (2018) Commentary:

Malaria elimination in India and

regional implications.

Front. Microbiol. 9:992.

doi: 10.3389/fmicb.2018.00992
Malaria elimination in India and regional implications

by Wangdi, K., Gatton, M. L., Kelly, G. C., Banwell, C., Dev, V., and Clements, A. C. A. (2016). Lancet Infect. Dis. 16, e214-e224. doi: 10.1016/S1473-3099(16)30123-2

Malaria has remained a greatest health and socioeconomic burden in the tropical and subtropical regions of the world. According to World Health Organization, approximately, 429,000 deaths with 212 million cases were reported from malaria in the world (World Health Organization, 2016a).

Wangdi et al. (2016) in their recent review in "Lancet Infectious Diseases" reported nationwide malaria elimination efforts and challenges in India and bordering countries as India contributes a substantial burden of malaria outside sub-Saharan Africa, with the third highest Plasmodium vivax prevalence in the world. Authors have discussed that India shares long international borders with Nepal, China, and Bhutan in the north, Bangladesh and Myanmar in the east, and Pakistan in the west. We agree that malaria remains a substantial public health problem in India and these bordering countries and a cross-border strategy and collaboration with these countries is vital to achieve the goals of malaria elimination in the region. Nevertheless, we felt it was important to draw attention and highlight other potentially significant aspects overlooked by this review according to our (Karim et al., 2016) and other reports (Directorate of Malaria Control Pakistan, 2015; World Health Organization, 2016a).

To highlight that the cross-country collaboration to control malaria is needed, we searched the prevalence (\%) of Plasmodium species in bordering countries of India. In additon, Ahghanistan was included in bordering countries of India because India shares longest land border with Bangladesh $(4,096.7 \mathrm{Km})$, China $(3,488 \mathrm{Km})$, and Pakistan $(3,323 \mathrm{Km})$ and it shares the shortest land border with Afghanistan $(106 \mathrm{Km})$ (Ministry of Home Affairs, Department of Border Management, 2018). China, Pakistan, and Afghanistan are the most populous countries affected by Plasmodium vivax malaria (World Health Organization, 2016b). Our epidemiological and clinical study of bordering region in Pakistan showed that $P$. vivax was the most prevalent species in the area especially alongside regions bordering the neighboring Afghanistan, exhibiting same genetic 
background (Karim et al., 2016). According to World Health Organization, the prevalence of $P$. vivax in Afghanistan is the highest (95\%) among all the bordering countries of India (World Health Organization, 2016b). The prevalence of $P$. vivax in the other bordering countries of India is highest in Pakistan (81\%), China (79\%), Nepal (78\%), and Bhutan (60\%) while its prevalence in Myanmar and Bangladesh is 34 and $7 \%$, respectively (Figure 1) (World Health Organization, 2016b). However, Plasmodium falciparum is predominant in Bangladesh (93\%) followed by Myanmar (66\%), Bhutan (40\%), Nepal (22\%), Pakistan (19\%), China (11\%), and Afghanistan (5\%) (Figure 1). These results suggest that the high prevalence of $P$. falciparum in Bangladesh and Myanmar is likely to contribute to its prevalence (67\%) in the northeast region of India (World Health Organization, 2016b). In addition, the high prevalence of $P$. vivax in Afghanistan, Pakistan, China, Nepal, and Bhutan is also likely to contribute to its incidence in the west and north regions of India (World Health Organization, 2016b). Therefore, the cross-country collaboration to control malaria is urgently needed.

$P$. falciparum was resistant against chloroquine throughout India but sensitive to mefloquine as echoed by Wangdi et al. (2016). However, in all seven bordering countries, extensive chloroquine drug resistance has been emerged in a high proportion (Centers for Disease Control and Prevention, 2017). According to a study, chloroquine resistance is associated

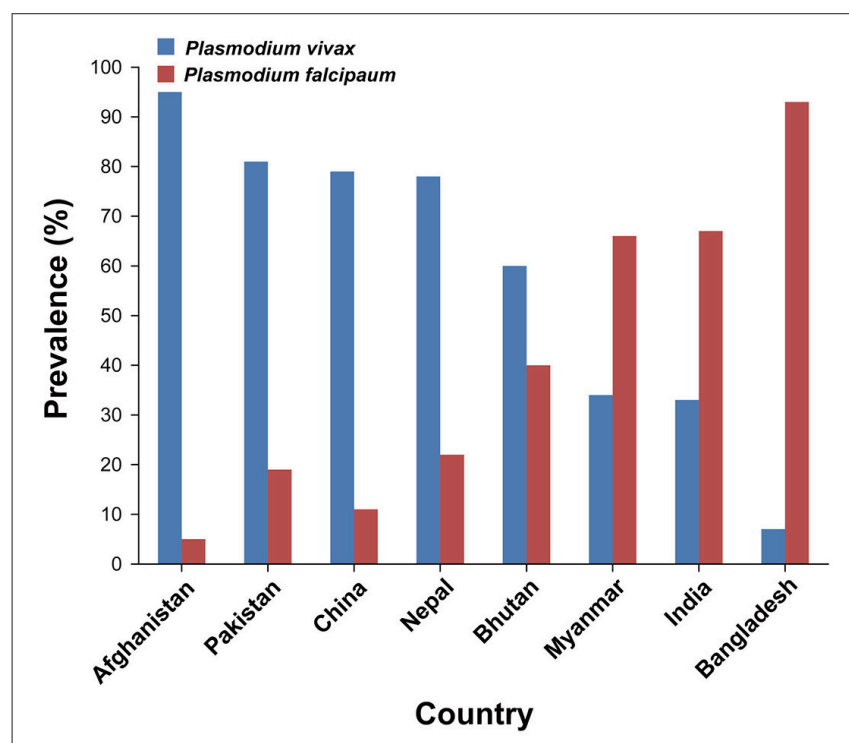

FIGURE 1 | Prevalence (\%) of Plasmodium species in India and its bordering countries. According to recent reports (World Health Organization, 2016b; Mercado et al., 2017), the numbers of confirmed malaria cases caused by Plasmodium vivax in India and its bordering countries were as follows: Afghanistan ( $n=98,208)$, Pakistan $(n=163,631)$, China $(n=31)$, Nepal $(n=$ 505), Bhutan ( $n=62)$, Myanmar $(n=62,141)$, India $(n=385,856)$, and Bangladesh ( $n=2,772$ ). The numbers of confirmed malaria cases caused by Plasmodium falciparum in India and its bordering countries were as follows: Afghanistan ( $n=5,169)$, Pakistan $(n=38,382)$, China $(n=4)$, Nepal $(n=$ 142), Bhutan ( $n=42)$, Myanmar $(n=120,626)$, India $(n=783,405)$, and Bangladesh $(n=36,828)$. with point mutations in the $p f c r t$ ( $P$. falciparum chloroquine resistance transporter) gene in this fatal human malaria parasite (Pulcini et al., 2015). Additionally, Plasmodium species from Myanmar and China are resistant to chloroquine as well as mefloquine (Centers for Disease Control and Prevention, 2017). Resistance in P. falciparum to mefloquine is associated with increased expression of $p f m d r 1$ ( $P$. falciparum multidrugresistant gene 1) gene (Preechapornkul et al., 2009). As the case of chloroquine resistance, there can be mefloquineresistant Plasmodium species exchange between India and the bordering countries. It is more probable that higher antimalarial chloroquine and mefloquine resistance in neighboring Myanmar, Bangladesh, and Pakistan can contribute to increasing resistance in India. (Ghanchi et al., 2011; Wangdi et al., 2016). Previous studies in Southeast Asia have shown that $P$. vivax isolates with pvmdr1 ( $P$. vivax multidrug-resistant gene 1) gene amplification were characterized by increased susceptibility to chloroquine but decreased susceptibility to mefloquine (Imwong et al., 2008; Suwanarusk et al., 2008). Nevertheless, the role of pvmdr1 in conferring resistance to chloroquine is still elusive and controversial (Faway et al., 2016). Although number of pvmdr1 gene copies correlated with mefloquine use history, in vivo data showing a direct relationship between mefloquine resistance and pvmdr1 gene amplification form mefloquine-treated patients are needed (Khim et al., 2014). Therefore, further studies are needed to identify trustworthy gene(s) for chloroquine and mefloquine resistance in $P$. vivax.

Kinley Wangdi and colleagues have highlighted the malaria elimination efforts carried out by the neighboring countries, however, they did not mention the Malaria Control Programme of Pakistan bordering Gujarat and Rajasthan, the high malaria transmission western states of India (Wangdi et al., 2016). In 2015, the Government of Pakistan ensured the reinforcement of surveillance and assessment programmes in the country (Directorate of Malaria Control Pakistan, 2015). According to this malaria strategic plan (by 2020), the main goal is to reduce malaria burden by $75 \%$ in high and moderate endemic areas and eliminate malaria from low endemic areas of Pakistan, in collaboration with Global Malaria Plan of Action and Global Technical Strategy 2015-20 (Directorate of Malaria Control Pakistan, 2015). Pakistan has made substantial progress in reducing malaria after the implementation of program. The country has achieved lowest annual parasite incidence in Punjab and Azad Kashmir provinces (Directorate of Malaria Control Pakistan, 2016). In 2016, Pakistan was able to make considerable progress in terms of enhanced coverage of malaria control interventions in endemic districts including malaria case management, distribution of Long Lasting Insecticidal Nets (LLINs) and Behavior Change Communication (BCC) activities. As compared to year 2015 (no of LLINs $=1.74$ million), 2.4 million LLINs were distributed in the country during 2016. Therefore, these malaria control interventions will help to reduce infection in the future (Directorate of Malaria Control Pakistan, 2016). Therefore, a cross-border malaria elimination strategy between India and Pakistan is urgently needed.

Wangdi and colleagues have overlooked the malaria deaths and prevalence in children. According to WHO, "A child dies of 
malaria every 2 minutes" (World Health Organization, 2016a). Of 429,000 deaths, 303,000 malaria deaths occurred in children aged under 5 years (World Health Organization, 2016a). Malaria is one of the world's top killer diseases for the young children. According to our study, children are more susceptible to malarial parasite because they have not yet developed immunity against malaria (Karim et al., 2016). Therefore, efforts aimed at the prevention of malaria in young children must be multifaceted. We emphasize that insect avoidance is critical in children and it can prevent the malaria acquisition in them. Rapid diagnosis and treatment of malaria infection are very useful to limit morbidity and mortality caused by it. Cross-border collaboration and global and regional efforts to combat malaria are very critical to achieve the goals of its elimination in the region.

\section{REFERENCES}

Centers for Disease Control and Prevention (2017). Malaria Information and Prophylaxis, by Country. Available online at: https://www.cdc.gov/malaria/ travelers/country_table/a.html

Directorate of Malaria Control Pakistan (2015). Available online at: http://dmc. gov.pk/documents/pdfs/1National\%20Malaria-Strategic\%20Plan-Pakistan.pdf

Directorate of Malaria Control Pakistan (2016). Available online at: http://dmc. gov.pk/documents/pdfs/Malaria\%20Annual\%20Report\%202016.pdf

Faway, E., Musset, L., Pelleau, S., Volney, B., Casteras, J., Caro, V., et al. (2016). Plasmodium vivax multidrug resistance-1 gene polymorphism in French Guiana. Malar. J. 15, 540. doi: 10.1186/s12936-016-1595-9

Ghanchi, N. K., Ursing, J., Beg, M. A., Veiga, M. I., Jafri, S., and Mårtensson, A. (2011). Prevalence of resistance associated polymorphisms in Plasmodium falciparum field isolates from southern Pakistan. Malar. J. 10:18. doi: 10.1186/1475-2875-10-18

Imwong, M., Pukrittayakamee, S., Pongtavornpinyo, W., Nakeesathit, S., Nair, S., Newton, P., et al. (2008). Gene amplification of the multidrug resistance 1 gene of Plasmodium vivax isolates from Thailand, Laos, and Myanmar. Antimicrob. Agents Chemother. 52, 2657-2659. doi: 10.1128/AAC.01459-07

Karim, A. M., Hussain, I., Malik, S. K., Lee, J. H., Cho, I. H., Kim, Y. B., et al. (2016). Epidemiology and clinical burden of malaria in the wartorn area, Orakzai Agency in Pakistan. PLoS Negl. Trop. Dis. 10:e0004399. doi: 10.1371/journal.pntd.0004399

Khim, N., Andrianaranjaka, V., Popovici, J., Kim, S., Ratsimbasoa, A., Benedet, C., et al. (2014). Effects of mefloquine use on Plasmodium vivax multidrug resistance. Emerg. Infect. Dis. 20, 1637-1644. doi: 10.3201/eid2010.140411

Mercado, C. E. G., Ekapirat, N., Dondorp, A. M., and Maude, R. J. (2017). An assessment of national surveillance systems for malaria elimination in the Asia Pacific. Malar. J. 16, 127. doi: 10.1186/s12936-017-1774-3

Ministry of Home Affairs, Department of Border Management (2018). Available online at: https://mha.gov.in/sites/default/files/Mandate_Border_II_16022018. PDF

\section{AUTHOR CONTRIBUTIONS}

All authors listed have made a substantial, direct and intellectual contribution to the work, and approved it for publication.

\section{ACKNOWLEDGMENTS}

Work in SHL's lab is supported by research grants from the Bio \& Medical Technology Development Program of the NRF funded by the MSIT (numbers NRF-2017M3A9E4078009 and NRF-2017M3A9E4078014); and the National Research Foundation of Korea (NRF) funded by the Ministry of Science and ICT (number NRF-2017R1A2B4002315). We also thank Raunda Ho for proofreading and helpful suggestion on the manuscript.

Preechapornkul, P., Imwong, M., Chotivanich, K., Pongtavornpinyo, W. Dondorp, A. M., Day, N. P. J., et al. (2009). Plasmodium falciparum pfmdr1 amplification, mefloquine resistance, and parasite fitness. Antimicrob. Agents Chemother. 53, 1509-1515. doi: 10.1128/AAC.00241-08

Pulcini, S., Staines, H. M., Lee, A. H., Shafik, S. H., Bouyer, G., Moore, C. M., et al. (2015). Mutations in the Plasmodium falciparum chloroquine resistance transporter, PfCRT, enlarge the parasite's food vacuole and alter drug sensitivities. Sci. Rep. 5:14552. doi: 10.1038/srep14552

Suwanarusk, R., Chavchich, M., Russell, B., Jaidee, A., Chalfein, F., Barends, M., et al. (2008). Amplification of pvmdr1 associated with multidrugresistant Plasmodium vivax. J. Infect. Dis. 198, 1558-1564. doi: 10.1086/5 92451

Wangdi, K., Gatton, M. L., Kelly, G. C., Banwell, C., Dev, V., and Clements, A. C. A. (2016). Malaria elimination in India and regional implications. Lancet Infect. Dis. 16, e214-e224. doi: 10.1016/ S1473-3099(16)30 123-2

World Health Organization (2016a). World Malaria Report. Geneva. Available online at: http://apps.who.int/iris/bitstream/10665/252038/1/9789241511711eng.pdf

World Health Organization (2016b). Malaria Country Profiles 2016. Available online at: http://www.who.int/malaria/publications/country-profiles/en/

Conflict of Interest Statement: The authors declare that the research was conducted in the absence of any commercial or financial relationships that could be construed as a potential conflict of interest.

Copyright (c) 2018 Park, Malik, Lee, Karim and Lee. This is an open-access article distributed under the terms of the Creative Commons Attribution License (CC $B Y)$. The use, distribution or reproduction in other forums is permitted, provided the original author(s) and the copyright owner are credited and that the original publication in this journal is cited, in accordance with accepted academic practice. No use, distribution or reproduction is permitted which does not comply with these terms. 